\title{
ПОВЫШЕНИЕ СОДЕРЖАНИЯ БЕТАИНОВ В ЗЕРНЕ КАК ПЕРСПЕКТИВНОЕ НАПРАВЛЕНИЕ СЕЛЕКЦИИ ДЛЯ ПОЛУЧЕНИЯ ФУНКЦИОНАЛЬНЫХ ПРОДУКТОВ ПИТАНИЯ (ОбЗОр)
}

\author{
V.I. Polonsky, A.V. Sumina
}

\section{THE INCREASE OF BETAIN CONTENT IN GRAIN AS A PROMISING DIRECTION OF SELECTION FOR RECEIVING FUNCTIONAL FOOD (review)}

Полонский Вадим Игоревич - д-р биол. наук, проф. каф. ландшафттнй архитектуры, ботаники, агроэкологии Красноярского государственного аграрного университета, г. Красноярск.

E-mail: vadim.polonskiy@mail.ru

Сумина Алена Владимировна - канд. с.-х. наук, доц. каф. химии и геоэкологии Хакасского государственного университета им. Н.Ф. Катанова, г. Абакан. E-mail: alenasumina@list.ru

В последнее время в мире резко возрос интерес к функциональным продуктам питания. Согласно Доктрине продовольственной безопасности РФ, в ближайшей перспективе предполагается расширение ассортимента продуктов здорового питания населения. Поэтому необходим поиск соответствующих пищевых источников. К веществам, способствующим профилактике ряда серьезных заболеваний человека, относится бетаин. Показано, что цельное зерно пшеницы характеризуется как весьма хороший источник бетаина, содержит его в 4-5 раз больше по сравнению с рафинированным зерном. Установлено, что на содержание бетаина в зерновых культурах заметное влияние оказывает генотип, в частности зафриксированы существенные различия в содержании указанного вещества у культурных видов и диких форм злаков. Найдено, что уровни бетаина наиболее сильно различаются между видами, при этом сортовая специфика его содержания в зерновых культурах изучена в настоящее время довольно слабо. Имеющаяся инсрормация о количестве бетаина в зерне различных злаков может быть полезной для селекции форм с повышенным содержанием бетаина в зерне. Указанный путь в принципе возможен исходя из существенной зависимости этого качественного признака
Polonsky Vadim Igorevich - Dr. Biol. Sci., Prof., Chair of Landscape Architecture, Botany, Agroecology, Krasnoyarsk State Agrarian University, Krasnoyarsk.

E-mail: vadim.polonskiy@mail.ru

Sumina Alyona Vladimirovna - Cand. Agr. Sci., Assoc. Prof., Chair of Chemistry and Geoecology, N.F. Katanov Khakass State University, Abakan. E-mail: alenasumina@list.ru

om генотипа, а также из полученных экспериментальных данных об удвоении уровня бетаина в семенах модельного растения арабидопсиса методом генной инженерии. К сожалению, экспериментальных данных о содержании в зерновых культурах бетаина имеется недостаточно. С целью привлечения внимания генетиков, селекционеров, физиологов растений, биотехнологов и растениеводов к указанной проблеме читателю предлагается обзор современной литературы.

Ключевые слова: содержание бетаинов, функкциональные продукты питания, здоровье человека, зерновые злаки, пшеница, алейроновый слой, генотип, условия выращивания, селекция

In recent years the world's interest in functional food has dramatically grown. According to the Doctrine of food security of the Russian Federation in the nearest future it is expected to expand the range of healthy food products for the population. Therefore, it is necessary to look for appropriate food resources. Betaine belongs to the substances promoting the prevention of a number of serious diseases of the man. It is shown that the whole grain of wheat is characterized as a very good source of betaine, containing it 4-5 times more than refined grain. It is established that the content 
of betaine in cereals is significantly influenced by the genotype; in particular, significant differences in the content of this substance in cultivated species and wild forms of cereals have been recorded. It is found that the levels of betaine differ most significantly between the species, while varietal specificity of its content in cereals has been quite poorly studied. Available information on the amount of betaine in the grain of various cereals can be useful for the selection of forms with a high content of betaine in grain. This pathway is possible in principle, basing on significant dependence of this qualitative trait on the genotype, as well as on experimental data obtained on the doubling of betaine level by genetic engineering in the seeds of the model plant arabidopsis. Unfortunately, experimental data on the content of betaine in cereals are not enough. In order to attract the attention of geneticists, selectors, plant physiologists, biotechnologists and plant selectors to this problem, the reader is offered the review of modern literature.

Keywords: betaine content, functional food, human health, cereals, wheat, aleurone layer, genotype, growing conditions, selection.

Введение. В организме млекопитающих и человека роль бетаина заключается в поставке метильных групп для превращения непротеиногенной аминокислоты гомоцистеина в метионин. Бетаин поступает в организм человека с пищей, а также может синтезироваться путем окисления свободного холина [4]. Исследования функций бетаина, выполненные в последние годы, свидетельствуют о широком спектре его пользы для здоровья $[4,15]$. По этим причинам указанное химическое вещество сегодня используется в качестве ингредиента функцционального питания и пищевой добавки [6].

Содержание бетаина в продуктах переработки зерновых культур. Поскольку бетаин функционирует в клетках многих организмов как совместимый осмолит [1], то растительные продукты являются его диетическими источниками, хотя обыкновенно ассортимент пищи с высоким содержанием бетаина (более 150 мкг/г) имеет ограниченный выбор [5]. Широко известно, что к числу наиболее часто потребляемых человеком продуктов питания относятся зерновые злаки. Растущий интерес к бетаинам как природным соединениям, потенциально полезным для здо- ровья человека, побудил исследователей провести комплексное изучение их содержания в зерне злаков, которые представляют собой важнейшие источники питания для человека [16]. Как показано в литературе, зерновые продукты являются основным поставщиком бетаина в составе Западной диеты $[5,7,11,13]$. Найдено, что количество бетаина в белом хлебе, полученном из рафинированной пшеницы, варьирует от 174 до 287 мкг/г (или 360 мкг/г), в цельнозерновом хлебе - в пределах 560-620, а зерновых отрубях 2300-7200 мкг/г [13, 17]. При этом превышение содержания бетаина в пшеничных продуктах из цельного зерна по сравнению с рафинированными наблюдается не всегда, что может объясняться сортовыми различиями, как, например, в случае с твердой пшеницей [3], или разницей в потерях фрракции отрубей при измельчении и переработке пищевых продуктов [13].

Анализировали содержание бетаина в 54 образцах зерна различных культур злаков с помощью метода высокоэффективной жидкостной хроматографии. Установлено, что наибольшая концентрация рассматриваемого химического соединения регистрировалась в пшеничных отрубях. Смешанные зерновые продукты, такие как сухие завтраки, широко варьировали по содержанию бетаина благодаря разнообразному составу ингредиентов, который определялся различными зерновыми хлопьями, сухими фрруктами и фрракциями отрубей [7]. А. Росс (Ross A.) c коллегами [13] подтвердили фракт пониженного содержания бетаина в составе мюсли (менее 150 мкг/г). Манная крупа также характеризовалась низким содержанием бетаина (48 мг/100 г сухого вещества), а в муке из твердых сортов пшеницы уровень бетаина составил 31 мг/100 г сухого вещества [3]. Содержание бетаина в некоторых образцах и коммерчески доступных пищевых продуктах (крахмал, вспученное зерно, макаронные изделия, хлопья на основе кукурузы и риса, печенье, крекеры) было ниже предела его обнаружения $[10,13]$.

Содержание бетаина в различных частях зерновки. Что касается содержания бетаина в разных частях пшеничного зерна, то установлено, что уровни этого соединения наиболее высоки в алейроновом слое $(1115,867$ и 23 мг/100 г бетаина для алейроновых слоев, отрубей и муки 
соответственно) [8]. Этот фракт был подтвержден другими исследователями [12,13]. Появившиеся в последнее время новые методы измельчения и сухого фракционирования позволили полностью отделить клетки алейронового слоя от других участков пшеничных отрубей. Согласно имеющейся базе данных Министерства сельского хозяйства США о содержании бетаина в пищевых продуктах, разработанной С. Зейселом (Zeisel S.) с коллегами [19], самые высокие концентрации бетаина присутствуют в пшеничных отрубях и зародышах пшеницы (соответственно 1339 и 1241 мг/100 г). Известно, что содержание бетаина относительно высоко в пшеничных хлопьях $[5,14,19]$, а в цельном зерне пшеницы его находится в 4-5 раз больше по сравнению с рафиинированным зерном: 1086 против 239 мкг/г [2].

Зависимость содержания бетаинов в зерне от генотипа. Установлено, что на содержание бетаина в зерновых культурах заметное влияние оказывает генотип. Так, согласно опубликованным экспериментальным данным, полученным на 54 образцах злаков, по среднему содержанию бетаина в зерне образцы расположились следующим образом (в порядке увеличения): гречиха < просо < пшеница <овес < рожь $<$ ячмень < амарант < полба. По мнению авторов, зарегистрированные результаты могут быть использованы при разработке новых функциональных продуктов питания [10]. В другом исследовании было проанализировано содержание бетаинов в 72 коммерческих образцах из рафинированной муки 10 видов злаков. Согласно полученным данным, концентрации бетаинов в образцах составили следующие значения: кукуруза 2 мкг/г, рис 8, гречиха 10, сорго 42, овес 53, просо 132, мягкая пшеница 180, пшеница двузернянка 195, твердая пшеница 245, ячмень 255 , рожь 310 , пшеница однозернянка 367 мкг/г [16]. Найдено, что мука, полученная из зерна пшеницы спельты, является более богатым источником бетаина по сравнению с обыкновенной пшеницей (126 и 31 мг/100 г соответственно) [10]. В одной из работ были найдены высокие уровни бетаина в зерне овса - свыше $200 \mathrm{MKг} / \Gamma[5]$.

Подчеркнем, что сортовая специфика содержания бетаина в зерновых культурах сегодня изучена довольно слабо. Так, исследовали со- держание бетаина в зерне различных сортов ржи, ячменя, овса и нескольких видов пшеницы. Количественные уровни этого химического вещества составили следующие значения: рожь 153-176 мг/100 г, пшеница спельта 137-143, пшеница мягкая 98-132, пшеница двузернянка 83-94, голозерный ячмень 98, пленчатый ячмень 46, овес 28-44 мг/100 г. В целом содержание бетаина наиболее сильно различалось между видами. Из-за ограниченного числа доступных для измерения образцов авторы не смогли дать четкую интерпретацию влияния сорта на рассматриваемый качественный признак зерна [18].

Полученная информация о влиянии генотипа на содержание бетаина в зерне злаков может быть полезной при выборе источников с высоким его содержанием в целях улучшения диеты за счет введения фрункциональных продуктов питания [18], а также для направленной селекции сортов с повышенным содержанием бетаина в зерне. Последнее в принципе возможно исходя из существенной зависимости указанного качественного признака от генотипа, а также из экспериментальных данных, опубликованных в работе [9]. Целью последней было снижение содержания синапина и одновременное повышение уровня холина и бетаина в семенах крестоцветных. Методом генной инженерии авторам удалось удвоить содержание бетаина в семенах модельного растения арабидопсиса.

Зависимость содержания бетаинов в зерне от условий выращивания растений. 0 влиянии экологических условий, складывающихся при выращивании зерновых культур (климатические и погодные факторы, состав и состояние почвы и другое), на содержание в них бетаинов имеется следующая информация. Поскольку бетаин является основным осмолитом растений, его содержание в растениях зависит от условий их выращивания [3]. Показано, что климатические условия и уровень стресса, в котором находится зерновая культура, воздействуют на концентрацию бетаина в зерне. В частности, почвенная засуха может приводить к повышению уровня бетаина в зерновых культурах по сравнению с таковыми, выращенными на хорошо орошаемых полях [17]. Обнаруженное значительное изменение содержания бетаина и холина в зерновых продуктах аналогичных видов может быть следствием погодных или дру- 
гих изменений в окружающей среде либо взаимодействия генотипов со средой, что определяет почти 80 \% из полного отклонения содержания бетаина в зерне пшеницы и ржи $[3,13]$.

Заключение. Итак, к химическим веществам, способствующим профилактике ряда серьезных заболеваний человека, относится бетаин. Зерновые продукты относятся к основным пищевым источникам бетаина во многих группах населения. Показано, что цельное зерно пшеницы характеризуется как весьма хороший источник бетаина. Высокие концентрации этого химического вещества определены в пшеничных отрубях и зародышах пшеницы. При этом найдено, что уровни бетаина наиболее высоки в алейроновой фрракции зерна.

Установлено, что на содержание бетаина в зерновых культурах заметное влияние оказывает генотип, в частности зафиксированы существенные различия в содержании указанного вещества у культурных видов и диких форм злаков. Найдено, что уровни бетаина наиболее сильно различаются между видами, при этом сортовая специфика его содержания в зерновых культурах изучена в настоящее время довольно слабо. Условия выращивания растений также оказывают влияние на концентрацию бетаина в зерне. В последние годы в некоторых западных странах начаты работы по изучению содержания бетаина в различных культурных и диких видах злаков. В России работы, посвященные изучению этих важных химических соединений в зерне, практически полностью отсутствуют.

\section{Литература}

1. Ahmad R., Lim C.J., Kwon S.Y. Glycine betaine: A versatile compound with great potential for gene pyramiding to improve crop plant performance against environmental stresses // Plant Biotechnology Reports. 2013. - Vol. 7, № 1. - P. 49-57.

2. Bruce S.J., Guy P.A., Rezzi S., Ross A.B. Quantitative measurement of betaine and free choline in plasma, cereals and cereal products by isotope dilution LC-MS/MS //Journal of Agricultural and Food Chemistry. - 2010. Vol. 58, № 4. - P. 2055-2061.

3. Corol D.I., Ravel C., Raksegi M. Effects of genotype and environment on the contents of betaine, choline, and trigonelline in cereal grains //Journal of Agricultural and Food Chemistry. - 2012. - Vol. 60, № 21. P. 5471-5481.

4. Craig S.A. Betaine in human nutrition // American Journal of Clinical Nutrition. - 2004. Vol. 80, № 3. - P. 539-549.

5. de Zwart F.J., Slow S., Payne R.J. Glycine betaine and glycine betaine analogues in common foods // Food Chemistry. - 2003. Vol. 83, № 2. - P. 197-204.

6. Filipcev B., Krulj J., Kojic J. Quality attributes of cookies enriched with betaine // Food Technology, Quality and Safety: III international congress (25-27.10.2016). - Novi Sad. P. $46-51$.

7. Gao X., Wang Y., Randell E. [et al.]. Higher dietary choline and betaine intakes are associated with better body composition in the adult population of Newfoundland, Canada // PloS one. - 2016. - Vol. 11. - P. e0155403.

8. Graham S.F., Hollis J.H., Miguad M. Analysis of betaine and choline content of aleurone, bran, and flour fractions of wheat (Triticum aestivum $\mathrm{L}$.) using (1) $\mathrm{H}$ nuclear magnetic resonance (NMR) spectroscopy //Journal of Agricultural and Food Chemistry. - 2009. Vol. 57, № 5. - P. 1948-1951.

9. Huang J., Rozwadowski K., Bhinu V.S. Manipulation of sinapine, choline and betaine accumulation in Arabidopsis seed: Towards improving the nutritional value of the meal and enhancing the seedling performance under environmental stresses in oilseed crops // Plant Physiology and Biochemistry: - 2008. Vol. 46, № 7. - P. 647-654.

10. Kojic J., Krulj J., Ilic N. Analysis of betaine levels in cereals, pseudocereals and their products // Journal of Functional Foods. - 2017. Vol. 37, № 1. - P. 157-163.

11. Likes R., Madl R.L., Zeisel S.H. The betaine and choline content of a whole wheat flour compared to other mill streams // Journal of Cereal Science. - 2007. - Vol. 46, № 1. P. 93-99.

12. Price R.K., Keaveney E.M., Hamill L.L. Consumption of wheat aleurone-rich foods increases fasting plasma betaine and modestly decreases fasting homocysteine and LDL cho- 
lesterol in adults // Journal of Nutrition. - 2010. - Vol. 140, № 12. - P. 2153-2157.

13. Ross A.B., Zangger A., Guiraud S.P. Cereal foods are the major source of betaine in the Western diet - Analysis of betaine and free choline in cereal foods and updated assessments of betaine intake // Food Chemistry. 2014. - Vol. 145, № 7. - P. 859-865.

14. Sakamoto A., Nishimura Y., Ono H. Betaine and homocysteine concentrations in foods //Pediatrics International. - 2002. - Vol. 44, № 3. - P. 409-413.

15. Schwahn B.C., Hafner D., Hohlfeld T. Pharmacokinetics of oral betaine in healthy subjects and patients with homocystinuria // British Journal of Clinical Pharmacology. - 2003. Vol. 55, № 1. - P. 6-13.

16. Servillo L., D'Onofrio N., Giovane A. The betaine profile of cereal flours unveils new and uncommon betaines // Food Chemistry. 2018. - Vol. 239, № 2. - P. 234-241.

17. Slow S., Donnaggio M., Cressey P.J. The betaine content of New Zealand foods and estimated intake in the New Zealand diet // Journal of Food Composition and Analysis. - 2005. - Vol. 18, № 3. - P. 473-485.

18. Tiihonen K.K., Riihinen K., Lyyra M. Authorised EU health claims for betaine // Foods, Nutrients and Food Ingredients with Authorised Eu Health Claims. Woodhead Publishing, 2014. - Chapter 12. - P. 251-273.

19. Zeisel S.H., Mar M.H., Howe J.C. Concentrations of choline containing compounds and betaine in common foods // Journal of Nutrition. - 2003. - Vol. 133. - P. 1302-1307.

\section{Literatura}

1. Ahmad R., Lim C.J., Kwon S.Y. Glycine betaine: A versatile compound with great potential for gene pyramiding to improve crop plant performance against environmental stresses // Plant Biotechnology Reports. 2013. - Vol. 7, № 1. - P. 49-57.

2. Bruce S.J., Guy P.A., Rezzi S., Ross A.B. Quantitative measurement of betaine and free choline in plasma, cereals and cereal products by isotope dilution LC-MS/MS //Journal of Agricultural and Food Chemistry. - 2010. Vol. 58, № 4. - P. 2055-2061.
3. Corol D.I., Ravel C., Raksegi M. Effects of genotype and environment on the contents of betaine, choline, and trigonelline in cereal grains //Journal of Agricultural and Food Chemistry. - 2012. - Vol. 60, № 21. P. 5471-5481.

4. Craig S.A. Betaine in human nutrition //American Journal of Clinical Nutrition. 2004. - Vol. 80, № 3. - P. 539-549.

5. de Zwart F.J., Slow S., Payne R.J. Glycine betaine and glycine betaine analogues in common foods // Food Chemistry. - 2003. Vol. 83, № 2. - P. 197-204.

6. Filipcev B., Krulj J., Kojic J. Quality attributes of cookies enriched with betaine // Food Technology, Quality and Safety: III international congress (25-27.10.2016). - Novi Sad. P. 46-51.

7. Gao X., Wang Y., Randell E. [et al.]. Higher dietary choline and betaine intakes are associated with better body composition in the adult population of Newfoundland, Canada /I PloS one. - 2016. - Vol. 11. - P. e0155403.

8. Graham S.F., Hollis J.H., Miguad M. Analysis of betaine and choline content of aleurone, bran, and flour fractions of wheat (Triticum aestivum L.) using (1) $\mathrm{H}$ nuclear magnetic resonance (NMR) spectroscopy // Journal of Agricultural and Food Chemistry. - 2009. Vol. 57, № 5. - P. 1948-1951.

9. Huang J., Rozwadowski K., Bhinu V.S. Manipulation of sinapine, choline and betaine accumulation in Arabidopsis seed: Towards improving the nutritional value of the meal and enhancing the seedling performance under environmental stresses in oilseed crops // Plant Physiology and Biochemistry. - 2008. Vol. 46, № 7. - P. 647-654.

10. Kojic J., Krulj J., Ilic N. Analysis of betaine levels in cereals, pseudocereals and their products // Journal of Functional Foods. - 2017. Vol. 37, № 1. - P. 157-163.

11. Likes R., Madl R.L., Zeisel S.H. The betaine and choline content of a whole wheat flour compared to other mill streams // Journal of Cereal Science. - 2007. - Vol. 46, № 1. P. 93-99.

12. Price R.K., Keaveney E.M., Hamill L.L. Consumption of wheat aleurone-rich foods increases fasting plasma betaine and modestly 
decreases fasting homocysteine and LDL cholesterol in adults // Journal of Nutrition. - 2010. - Vol. 140, № 12. - P. 2153-2157.

13. Ross A.B., Zangger A., Guiraud S.P. Cereal foods are the major source of betaine in the Western diet - Analysis of betaine and free choline in cereal foods and updated assessments of betaine intake // Food Chemistry. 2014. - Vol. 145, № 7. - P. 859-865.

14. Sakamoto A., Nishimura $Y$., Ono H. Betaine and homocysteine concentrations in foods I/Pediatrics International. - 2002. - Vol. 44, № 3. - P. 409-413.

15. Schwahn B.C., Hafner D., Hohlfeld T. Pharmacokinetics of oral betaine in healthy subjects and patients with homocystinuria // British Journal of Clinical Pharmacology. - 2003. Vol. 55, № 1. - P. 6-13.
16. Servillo L., D'Onofrio N., Giovane A. The betaine profile of cereal flours unveils new and uncommon betaines // Food Chemistry. 2018. - Vol. 239, № 2. - P. 234-241.

17. Slow S., Donnaggio M., Cressey P.J. The betaine content of New Zealand foods and estimated intake in the New Zealand diet // Journal of Food Composition and Analysis. - 2005. - Vol. 18, № 3. - P. 473-485.

18. Tiihonen K.K., Riihinen K., Lyyra M. Authorised EU health claims for betaine // Foods, Nutrients and Food Ingredients with Authorised Eu Health Claims. Woodhead Publishing, 2014. - Chapter 12. - P. 251-273.

19. Zeisel S.H., Mar M.H., Howe J.C. Concentrations of choline containing compounds and betaine in common foods // Journal of Nutrition. - 2003. - Vol. 133. - P. 1302-1307. 